\title{
Genome Engineering with Synthetic Copper Nucleases
}

\section{N. Fantoni \\ T. Lauria \\ A. Kellett*}

School of Chemical Sciences, National Institute for Cellular Biotechnology (NICB) and Nano-Bioanalytical Research Facility (NRF), Dublin City University, Glasnevin, Dublin 9, Ireland andrew.kellett@dcu.ie

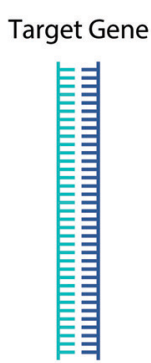

Received: 21.09.2015

Accepted after revision: 26.10.2015

Published online: 11.11 .2015

DOI: 10.1055/s-0035-1560709; Art ID: st-2015-p0754-sp

License terms: CC (i)

Abstract Oxidative chemical nucleases represent an important class of synthetic compound that mediate nucleic acid recognition and strand scission. These agents have found utility as footprinting probes to map drug-DNA and protein-DNA interactions and also as clinical cytotoxins of human cancer. Herein, we highlight a recent contribution from our group on the application of the copper(II) 1,10-phenanthroline (OP) complex $\mathrm{Cu}(\mathrm{OP})_{2}$ as a novel DNA-shuffling agent capable of generating highly diverse mutant protein antibody libraries. By employing a recombinant antibody gene fragment specific for prostate-specific antigen (PSA), we compared variation and PSA-binding specificity within Taq DNA polymerase I reconstructed $\mathrm{Cu}(\mathrm{OP})_{2}$ oxidative digest fragments with hydrolytic restriction digests generated by DNase I. Results show the $\mathrm{Cu}(\mathrm{OP})_{2}$ mutant library contained highly PSA-specific binding antibodies thus indicating that oxidative chemical nucleases may be applied to generate novel antibody clones not accessible through the use of the traditional DNA-shuffling enzyme DNase I.

Key words copper(II), nuclease, nucleic acids, radical oxidation, $\mathrm{H}$-atom abstraction, strand scission

In the field of DNA manipulation, the design of artificial DNA cutters has become an area of considerable research interest. Synthetic copper chemical nucleases are a class of DNA cutter and can be categorised in two ways: i) those that mimic natural restriction endonucleases by catalysing hydrolysis of the phosphodiester backbone, ${ }^{1}$ and ii) compounds that induce direct strand scission by oxidative $\mathrm{H}-$ atom abstraction from the pentose ring of DNA. ${ }^{2}$ The biochemistry of bovine pancreatic deoxyribonuclease (DNase I) - a calcium- and magnesium-dependent hydrolytic enzyme that nonspecifically degrades both single- and double-stranded DNA - is described in Scheme 1 (A). Here, glutamate (Glu75) and histidine (His131) residues combine to
Oxidative Scission

Shuffled Fragment
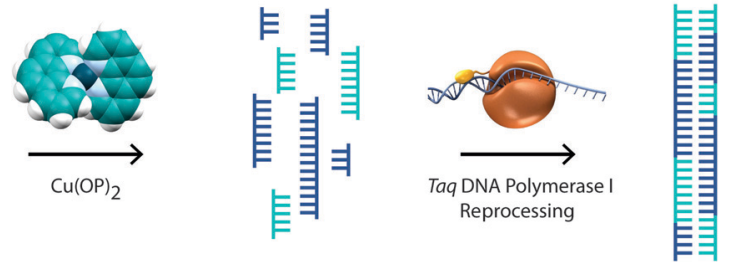

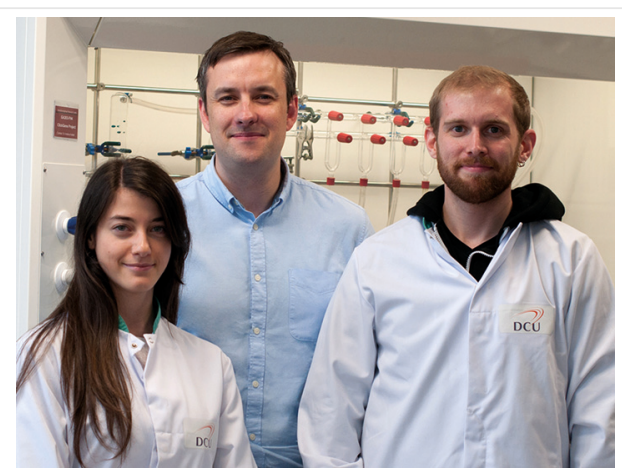

Andrew Kellett (centre) is principle investigator and lecturer of medicinal inorganic chemistry in the School of Chemical Sciences at Dublin City University, Ireland. His group are based at the National Institute for Cellular Biotechnology and Nano-Bioanalytical Research Facility and focus on discovery of metallodrug-nucleic acid interactions for biochemical and therapeutic application. He is coordinator of the Horizon 2020 Marie Skłodowska-Curie Innovative Training Network (ITN), ClickGene, and his lab is also supported by the Irish Research Council and the Science Foundation Ireland funded Synthesis and Solid-State Pharmaceutical Centre. He completed his BSc in chemistry from NUI Maynooth, received his PhD under the guidance of Prof. M. Devereux at the Dublin Institute of Technology (DIT) in 2007, and was then appointed as A.F. Graves Postdoctoral Fellow at the Focas Research Institute until 2011. Teresa Lauria (left) was born in Naples, Italy. She studied chemistry at the University of Naples Federico II receiving her MSc degree in 2014 for work on nucleic acids chemistry. She then joined the Kellett group as a Marie Curie PhD student within the ClickGene ITN Project.

Nicolò Fantoni (right) was born in Padova, Italy. He studied chemistry at the University of Padova receiving his MSc degree in 2014 for work in bioinorganic chemistry. In 2015 he joined the Kellett group as a Marie Curie PhD student within the ClickGene ITN project.

catalyse hydroxide anion formation in proximity to the phosphate backbone. ${ }^{3}$ The resulting 5 '-phosphorylated and 3'-hydroxylated ends produced by hydrolytic nucleases (e.g., DNase I or site-specific restriction endonucleases) can then be further manipulated, for example, in DNA recombi- 
nation. Oxidative chemical nucleases, on the other hand, such as the copper(II) 1,10-phenanthroline (OP) complex $\mathrm{Cu}(\mathrm{OP})_{2}$ (Scheme 1,C) induce direct strand scission on duplex DNA in the presence of exogenous reductant and oxidant. ${ }^{4}$ Our group actively explore the biochemical and therapeutic applications of $\mathrm{Cu}(\mathrm{OP})_{2}$-based systems and have recently applied this oxidative nuclease to genetically engineer a library of high-affinity prostate-specific antigen (PSA) binding antibodies through a process called DNA shuffling. ${ }^{5}$ In this work, the selectivity and diversity of the $\mathrm{Cu}(\mathrm{OP})_{2}$ recombinant antibody library was then compared directly to a library of mutant PSA-specific antibodies generated by DNase I.

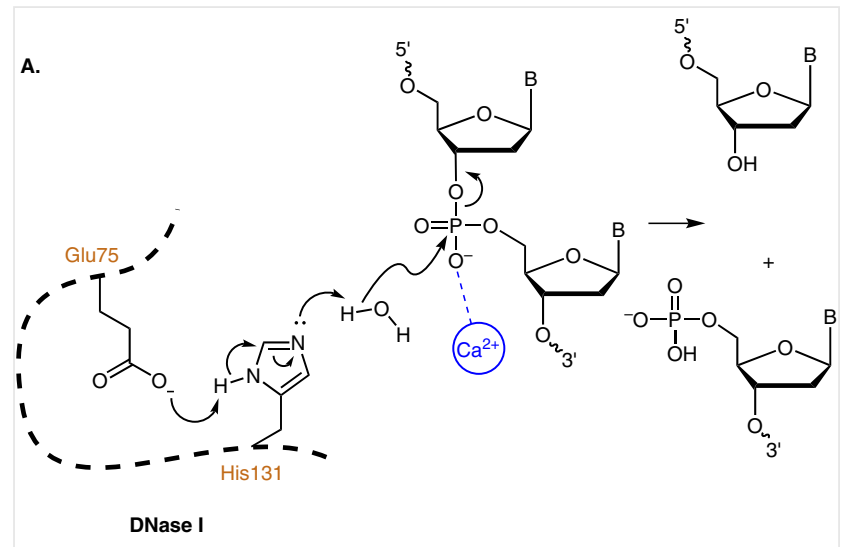

B.
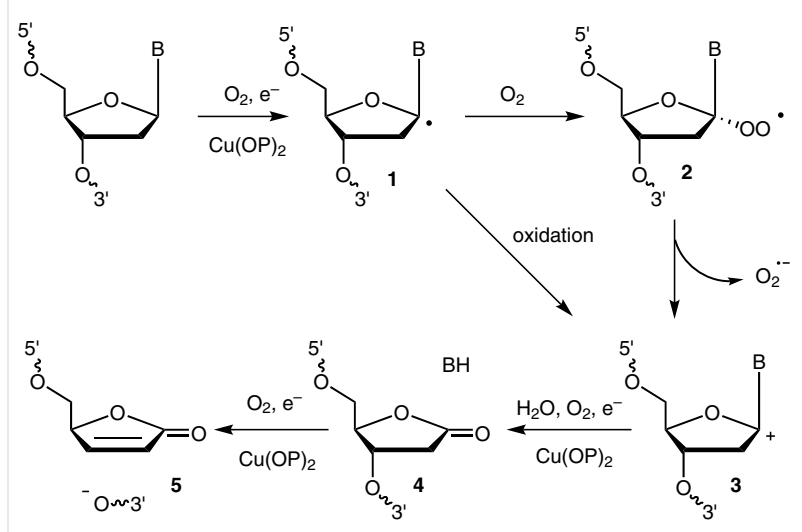

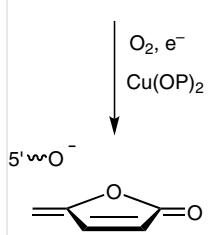

6

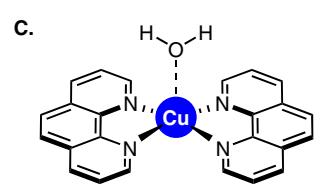

$\mathrm{Cu}(\mathrm{OP})_{2}$
Scheme 1 A. Hydrolytic cleavage mechanism by DNase I on the phosphodiester backbone of DNA. B. Radical oxidation mechanism by $\mathrm{Cu}(\mathrm{OP})_{2}$ producing direct strand break formation. C. Molecular structure of the $\left[\mathrm{Cu}(\mathrm{OP})_{2}\left(\mathrm{H}_{2} \mathrm{O}\right)\right]$ complex.
The artificial nuclease activity of $\mathrm{Cu}(\mathrm{OP})_{2}$ was discovered by Sigman in 1979 when the complex was observed to shear duplex DNA along A-T rich chains in the minor groove $^{4}$ with abstraction of $\mathrm{C}^{\prime}$-hydrogen predominating over C5' $^{\prime}$ and C4' positions. $^{6}$ Indeed, scission takes place preferentially in the minor groove on account of the binding interaction by the tetrahedral complex geometry assumed by $\mathrm{Cu}(\mathrm{OP})_{2}$ in its cuprous form. ${ }^{7}$

A seminal contribution to uncovering the oxidative mechanism by $\mathrm{Cu}(\mathrm{OP})_{2}$ was made by the Greenberg group (Scheme 1); using elegant experimental design, their work identified direct strand breakage via $\beta$-elimination of a 2 'deoxyribonolactone intermediate $\mathbf{4}$ and demonstrated the $\mathrm{Cu}(\mathrm{OP})_{2}$ complex behaving as general base catalyst. ${ }^{8,9}$ Thus, current evidence indicates the strand-scission mechanism proceeds through $\mathrm{H}$-atom abstraction at $\mathrm{C1}^{\prime}$ (1) followed, ostensibly, via the peroxyl radical intermediate $\mathbf{2}$ that expels superoxide $\left(\mathrm{O}_{2}^{--}\right)^{10}$ to generate the oxidised $\mathrm{C1}^{\prime}$ cation 3. The incorporation of ${ }^{18} \mathrm{O}$ into deoxyribonolactone (4) from $\mathrm{H}_{2}{ }^{18} \mathrm{O}$ has been established with the liberation of the free nucleobase (BH). ${ }^{6} \beta$-Elimination of $\mathbf{4}$ proceeds by general $\left[\mathrm{Cu}(\mathrm{OP})_{2}\right]$ base catalysis, and the final step in the mechanism sees the conversion of a 3 '-furanone (5) adduct to the free 5-methylene furanone $(\mathbf{6})$. The interaction of $\mathrm{Cu}(\mathrm{OP})_{2}$ with deoxyguanosine was further studied by our group and shown to generate 8-oxo-7,8-dihydro-2'-deoxyguanosine (8-oxo-dG) lesions within superhelical plasmid DNA (Scheme 2) using the enzyme-linked immunosorbent assay (ELISA). ${ }^{11}$
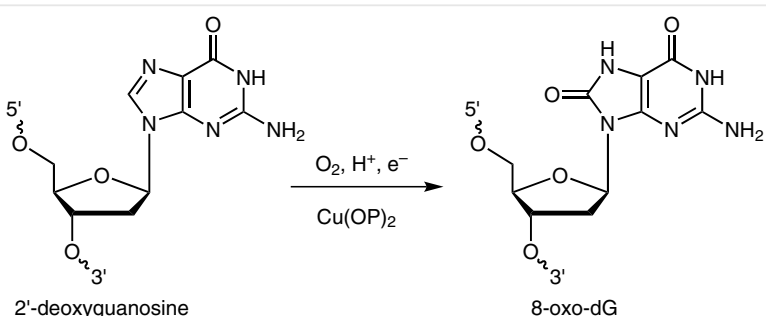

Scheme 2 Generation of the oxidative guanine lesion, 8-oxo-dG by $\mathrm{Cu}(\mathrm{OP})_{2}$

Until this point, both hydrolytic (DNase I) and oxidative [e.g., $\mathrm{Cu}(\mathrm{OP})_{2}$ ] nucleases have found widespread application as footprinting agents for the study of DNA recognition by proteins and small molecules. ${ }^{12}$ DNase I, however, has found further utility within the field of protein engineering through a process known as DNA shuffling (Figure 1,A) that was introduced in 1994 by Stemmer. ${ }^{13}$ This process - which is of great commercial importance toward enhancing the performance of target proteins in areas such as antibody affinity - involves the digestion of a parent gene by DNase I to form a mixture of shorter DNA fragments that are then reannealed by repeated thermocycling in the presence of a primerless DNA polymerase process. Shuffled DNA libraries can then be inserted into a larger piece of circular (plasmid) 
DNA and transformed into E. coli bacteria that, in turn, replicate these hybrid sequences and produce corresponding libraries of mutant antibody proteins. Recombinant DNA libraries can then be sequenced and antigen-binding affinity of newly produced antibodies accurately identified using technology such as surface plasmon resonance. Another method to achieve engineered protein libraries, staggered extension process (StEP), was developed by Arnold in 1998. ${ }^{14}$ This process prepares full-length recombinant genes (Figure 1,B) by firstly priming template sequences and then repeating cycles of denaturation and extremely short annealing and polymerase-catalysed extension. In this way, the growing fragments can anneal to a different template within each cycle and can thus acquire sequence information of different parental genes.
A.

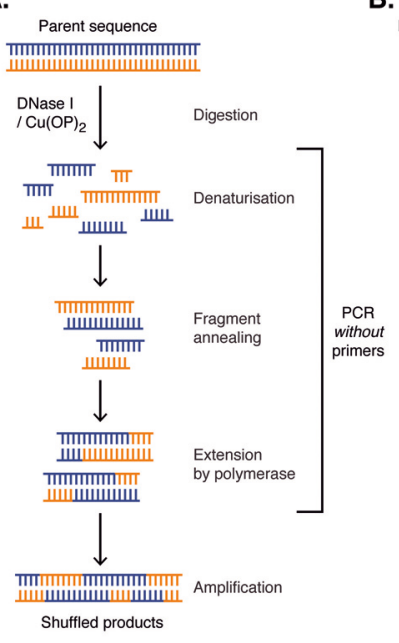

B.

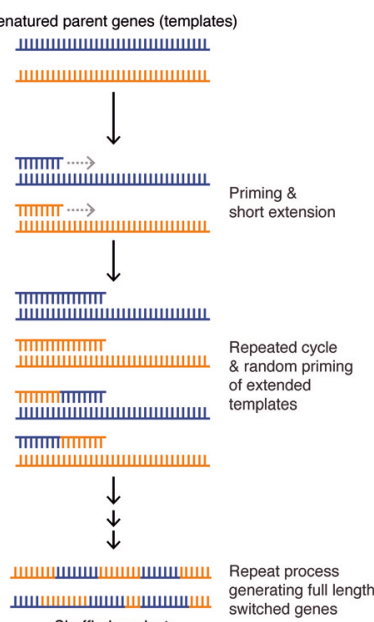

шшешшшшшшшшшшшше generating full len
switched genes Shuffled products
C.
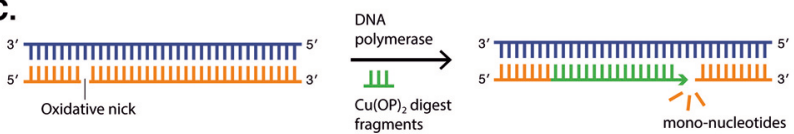

Figure 1 A. DNA shuffling through primerless PCR; B. staggered extension process (StEP); C. proposed DNA polymerase I catalysed nick translation.

In our recent contribution, we utilised the oxidative nuclease complex, $\left[\mathrm{Cu}(\mathrm{OP})_{2}\left(\mathrm{H}_{2} \mathrm{O}\right)\right] \cdot 2 \mathrm{NO}_{3}$, to generate a highly diverse recombinant library of PSA-specific antibodies through DNA polymerase I shuffling (Figure $1, \mathrm{~A}) .^{5}$ Although $\mathrm{Cu}(\mathrm{OP})_{\mathrm{x}}$ complexes have been unambiguously shown to inhibit the activity of a variety of DNA polymerase I enzymes, ${ }^{4,11}$ it has not yet been shown if purified oxidatively sheared fragments are suitable for polymerase 'reprocessing'. The complex (Scheme 1,C) was synthesised and characterised by single X-ray crystallography before exposure to a dsDNA gene fragment identified to produce PSA-specific antibodies by the ELISA. The digestion reaction was started by the addition of $1 \mu \mathrm{M}$ of $\mathrm{Cu}(\mathrm{OP})_{2}$ with $1 \mathrm{mM}$ of Na-L- ascorbate at pH 7.2 in the presence of $25 \mathrm{mM} \mathrm{NaCl}$. Under similar buffered conditions with the same DNA template, digestion was repeated using the traditional shuffling enzyme, DNase I. Digestion products were ethanol-precipitated and identified by agarose gel electrophoresis to have completely degraded the PSA gene sequence. The fragments obtained were then reannealed using the primerless polymerase chain reaction (PCR) method (Figure 1,A) and then amplified using specific forward and reverse primers to produce full-length gene fragments. It was significant to observe the successful reannealing process within the $\mathrm{Cu}(\mathrm{OP})_{2}$ restriction digest given our previous observation that T4 ligase did not religate oxidatively linearised pUC19. ${ }^{15}$ It was further observed that $\mathrm{Cu}(\mathrm{OP})_{2}$ digest religation and amplification produced a stunted shuffled gene fragment compared with DNase I. Thus, under these conditions a fraction of oxidatively sheared fragments are structurally unsuitable for DNA reprocessing by Thermus aquaticus (Taq) DNA polymerase I. It is clear, however, the $\mathrm{Cu}(\mathrm{OP})_{2}$ reaction proceeds to produce a fraction of intact 3 '- and 5'DNA fragments that are suitable for the PCR. Indeed, as outlined in Scheme $1(\mathrm{~B})$, direct strand breakage via $\mathrm{Cu}(\mathrm{OP})_{2}$ promoted $\beta$-elimination generates the intact 5 ' adduct through $\mathrm{C1}^{\prime}$ abstraction. Additionally, while Taq DNA polymerase I lacks a functional $3^{\prime} \rightarrow 5^{\prime}$ exonuclease, we hypothesise its functioning $\mathrm{N}$-terminal $5^{\prime} \rightarrow 3^{\prime}$ exonuclease ${ }^{16}$ may amplify dsDNA fragments nicked by $\mathrm{Cu}(\mathrm{OP})_{2}$ through the nick translation process (Figure 1,C).

Reannealed DNA sequences, from both DNase I and $\mathrm{Cu}(\mathrm{OP})_{2}$ experiments, were then ligated to vector samples using T4 DNA ligase for the subsequent amplification and phage display within $E$. coli XL-1 blue cells. Close to 60 clones expressed by both DNase I and $\mathrm{Cu}(\mathrm{OP})_{2}$ showed affinity for PSA and upon more detailed analysis using surface plasmon resonance, we identified that five of the top ten best-performing clones - including the top four derived from the $\mathrm{Cu}(\mathrm{OP})_{2}$ digested library. Additionally, DNA sequencing revealed very high levels of modification in the top-performing antibodies indicating $\mathrm{Cu}(\mathrm{OP})_{2}$ is capable of producing gene mutations not accessible through digestion with DNase I.

In summary, this work may potentially open a new application for copper(II) phenanthrene based compounds. Efforts to guide mutation to a specific gene segment might be achieved through the covalent linking of selective organic-based DNA binding molecules; indeed distamycin conjugates of copper-phenanthroline complexes have already been developed and identified as site-specific oxidative nucleases. ${ }^{8,17}$ Another layer of control toward target gene digestion can be envisaged through the introduction of noncovalent recognition elements - for example, our group has recently shown that netropsin (minor groove binder) hinders the general accessibility of $\mathrm{Cu}(\mathrm{OP})_{2}$ to the minor groove, the site of intensive DNA oxidation. ${ }^{11}$ Finally, the construction of designer intercalating ligands for incorpora- 
tion into copper(II) complex scaffolds may uncover new sites of oxidative dsDNA damage that, in turn, could enhance variation of genetic sequence mutation.

\section{Acknowledgment}

This work was supported by Science Foundation Ireland (13/TIDA/B2682), the Irish Research Council (GOIPG/2013/937) and the Marie Skłodowska-Curie Innovative Training Network (ITN) ClickGene (H2020-MSCA-ITN-2014-642023), http://www.clickgene.eu/.

\section{References}

(1) Mancin, F.; Scrimin, P.; Tecilla, P. Chem. Commun. 2012, 48, 5545.

(2) (a) Pitie, M.; Pratviel, G. Chem. Rev. 2010, 110, 1018. (b) Jiang, Q.; Xiao, N.; Shi, P. F.; Zhu, Y. G.; Guo, Z. J. Coord. Chem. Rev. 2007, 251, 1951.

(3) Suck, D.; Oefner, C. Nature 1986, 321, 620.

(4) Sigman, D. S.; Graham, D. R.; D’Aurora, V.; Stern, A. M. J. Biol. Chem. 1979, 254, 12269.

(5) Larragy, R.; Fitzgerald, J.; Prisecaru, A.; Mckee, V.; Leonard, P.; Kellett, A. Chem. Commun. 2015, 51, 12908.

(6) Meijler, M. M.; Zelenko, O.; Sigman, D. S. J. Am. Chem. Soc. 1997, 119,1135
(7) Sigman, D. S.; Bruice, T. W.; Mazumder, A.; Sutton, C. L. Acc. Chem. Res. 1993, 26, 98.

(8) Bales, B. C.; Pitie, M.; Meunier, B.; Greenberg, M. M. J. Am. Chem. Soc. 2002, 124, 9062.

(9) Chen, T. Q.; Greenberg, M. M. J. Am. Chem. Soc. 1998, 120, 3815.

(10) Gimisis, T.; Chatgilialoglu, C. Oxidatively Formed Sugar Radicals in Nucleic Acids, In Encyclopedia of Radicals in Chemistry, Biology and Materials; Vol. 3; Chatgilialoglu, C.; Studer, A., Eds.; Wiley: Hoboken, 2012, 1345.

(11) Molphy, Z.; Slator, C.; Chatgilialoglu, C.; Kellett, A. Front. Chem. 2015, 3.

(12) (a) Cardew, A. S.; Fox, K. R. DNase I Footprinting, In Drug-DNA Interaction Protocols; Vol. 613; Fox, K. R., Ed.; Humana Press: Totowa, 2010, 153-172. (b) Spassky, A.; Sigman, D. S. Biochemistry 1985, 24, 8050. (c) Basak, S.; Nagaraja, V. Nucleic Acids Res. 2001, 29, e105.

(13) Stemmer, W. P. C. Nature (London, U.K.) 1994, 370, 389.

(14) Zhao, H. M.; Giver, L.; Shao, Z. X.; Affholter, J. A.; Arnold, F. H. Nat. Biotechnol. 1998, 16, 258.

(15) Prisecaru, A.; Devereux, M.; Barron, N.; McCann, M.; Colleran, J.; Casey, A.; McKeee, V.; Kellett, A. Chem. Commun. 2012, 48, 6906.

(16) Eom, S. H.; Wang, J. M.; Steitz, T. A. Nature (London, U.K.) 1996, 382, 278.

(17) Bales, B. C.; Kodama, T.; Weledji, Y. N.; Pitie, M.; Meunier, B.; Greenberg, M. M. Nucleic Acids Res. 2005, 33, 5371. 